Francisco Javier Tardío Gastón

I. E. S Ildefonso Serrano

\title{
LA MUJER FATAL
}

Palabras clave: mujer, literatura, cine, femme fatale, crítica feminista

\section{Introducción}

Me empujaron a labios que dan felicidad, me separan, y me destruyen.

Goethe

Si nos situamos ante una pantalla y observamos el desenlace de la primera película hablada alemana, El Ángel Azul (1930), de Josef von Sternberg, la escena no puede ser más patética viendo a Emil Jannings interpretar a un hombre destruido, caído, que vende fotos de Lola-Lola mientras suena la voz de Marlene Dietrich, «Ten cuidado con las rubias».

Todas esas mujeres presentan una serie de características que las acercan a lo malvado y a la destrucción, usando sus encantos con el único fin de seducir y, de paso, destruir a los hombres. Desde tiempos remotos se ha identificado al hombre con el bien y a la mujer con el mal: en la mitología grecolatina, en la que se hacen presente sibilas, brujas $\mathrm{y}$ hechiceras, $\mathrm{y}$ en la tradición judeocristiana relacionando a la mujer con una serpiente o presentándola como bestia o prostituta.

Entonces vino uno de los siete ángeles que llevaban las siete copas y me habló: «ven que te voy a mostrar el juicio de la célebre Ramera, que se sienta sobre grandes aguas; con ella fornicaron los reyes de la tierra, y los habitantes de la tierra se embriagaron con el vino de su prostitución.» [...] La mujer estaba vestida de púrpura y escarlata, resplandecía de oro, piedras preciosas y perlas; llevaba en su mano una copa de oro llena de abominaciones, y también las impurezas de su prostitución. (Apocalipsis, 17: 1)

En este sentido se expresa González Ovies cuando afirma que «el género femenino, en los albores de la humanidad no desempeña otro papel, según testimonian pasajes, sino el de encarnar la fuerza del mal» (González Ovies, 1994). Ahora bien, ¿qué entendemos por mujer fatal, traducción de la expresión francesa femme fatale? Si nos acercamos al diccionario de la Real Academia Española vemos que se define como «aquella cuyo poder de atracción amorosa acarrea fin desgraciado a sí misma o a quienes atrae; referido principalmente a personajes de ficción, sobre todo de cine, y a las actrices que los representan». Dejando, de momento, a un lado la segunda parte de la definición, que será retomada al final del artículo, observamos que la connotación implícita de la definición acarrea la imagen de villana sexualmente insaciable que provocará con su intervención un final trágico. 
Este concepto de mujer es el que se pretende analizar en el presente artículo a través de diferentes ejemplos que han perfilado leyendas y obras de la literatura universal.

\section{Mujeres}

El mito de la mujer fatal, que se desarrolla a lo largo del siglo XIX, es la expresión de un tipo de mujer muy orgánica, activa, fuerte y carnal, a la vez que fascinante y dañina para el hombre, frente a otro modelo femenino mucho más pasivo, una mujer abnegada y sometida al varón (Dijkstra, 1994; Volpatti, 1994).

Se centra este arquetipo de mujer en el siglo XIX pero, sin embargo, si deseamos encontrar sus orígenes debemos remar hacia el pasado, a lo largo de toda la Historia, que nos llevará hasta los orígenes de nuestra tradición, allá en el horizonte donde se encuentra la Grecia clásica. Para identificar a la mujer como ser portador del pecado, del mal, se han destacado, tanto en la historia pagana como sagrada, características como la fragilidad moral y la inmadurez ética.

El arquetipo de mujer fatal existe en, prácticamente, todas las culturas (Wallace 1960: 236). Los orígenes del arquetipo de la mujer fatal se remontan a la mitología de la antigüedad. Posteriormente, el tipo de la mujer mortífera está omnipresente en el folclore popular y el arte de la cultura occidental. El arquetipo resurge en el romanticismo y florece particularmente en el arte de fines del siglo XIX y a inicios del siglo XX. (Houvenaghel 2008: 854)

Son muchos los casos de mujeres fatales que se han hecho conocidos a lo largo de la historia. Algunos parecen ser fiel representación de los hechos, pero en muchos otros se podría sospechar de algún tipo de enriquecimiento subjetivo por parte de las tradiciones orales y la libre interpretación. Un autor como José Manuel Camacho, por ejemplo, considera que Eva, si bien es presentada como débil ante la tentación, no es símbolo de maquinadora del engaño; es una mujer que tienta al hombre, pero no se percibe malicia en esto, sino una voluntad de compartir el descubrimiento con su pareja. Más bien fue un modelo que se utilizó para perfeccionar uno más sofisticado que se fue enriqueciendo hasta nuestros días (Camacho, 2006).

Como mujer que guarda similitudes con la Eva cristiana encontramos a Pandora. Sus apariciones las encontramos en las obras de Hesíodo: Teogonía, que contiene una versión del origen del cosmos y el linaje de los dioses de la mitología griega, y Trabajos y días. El autor griego considera a Pandora la primera mujer, que fue enviada al mundo como castigo, después que Prometeo robara el fuego del Olimpo para darlo a los hombres. Pandora poseía una impresionante belleza y una excesiva curiosidad, que la llevó a abrir la caja que le había entregado Zeus, con todos los males que azotan al mundo. Así pues, lo que une a Eva y a Pandora es el hecho de traer la desgracia a la humanidad.

Fue mi nacer conspiración divina,

Maléfico castigo, designado [...]

Mas mi espíritu estaba dominado 
De esa curiosidad que nos fascina $[\ldots]$

Hice de un Paraíso un cementerio. (Álvarez Hidalgo, Pandora, 1997)

También en la Grecia Clásica, Helena, fue una mujer que provocó, dejando a su marido Menelao y huyendo con Paris, la guerra de Troya. Otra fatal es Circe, que asesinó a su compañero sirviéndose de uno de sus brebajes de hechicera para reinar en solitario. Más tarde se dedicó a atraer y encantar a los marineros con el fin de robarles y transformarlos en bestias. Este comportamiento fue, en cierta medida, heredado por las sirenas, que con sus cantos confundían a los marineros y los hacían chocar contra los arrecifes. A este respecto Pilar Pedraza dice que, «los cantos de las sirenas están cargados de sentidos funestos,[...], y son engaños, anzuelos mágicos que tiende la muerte a los hombres a través de un atractivo monstruo de rostro virginal y corva garra» (Pedraza, 1991: 118).

Otra hechicera es Medea, que tras ser rechazada por Jasón para casarse con la princesa de Corinto, se vengó provocando la muerte de Glauca y matando a sus propios hijos, que tenía en común con Jasón.

Amor les sonreía. Mas la fatal esposa

llevábase consigo, colérica y celosa,

con su padre y los dioses, los filtros del oriente. (Heredia, Jasón y Medea, 1893)

Un ejemplo de feminidad perversa llamativo en la mitología griega, lo vemos en las Amazonas. Eran un pueblo de cazadoras y guerreras que usaban a los hombres sólo en cortos periodos, con el fin de procrear, y conservaban únicamente a las hijas, a las que les imponían matar a un enemigo antes de casarse. Si nacían hijos varones, les quitaban la vida o los mutilaban. Aparte de cubrir sus necesidades reproductivas, los hombres sólo podían permanecer a su lado como siervos. A pesar de su potencial guerrero, fueron derrotadas por los atenienses, pues - como se puede notar hasta ahora- toda figura femenina perversa merecía un castigo. Hay un sentimiento de culpabilidad de una sociedad masculina, miedo de los hombres a caer sumisos ante las mujeres. En este miedo de los hombres hacia las mujeres se sitúa la causa del gran menosprecio con que éstas son tratadas por la mitología, presentadas como seres terroríficos, hecho que contrasta con la situación real de discriminación que soportaban las mujeres griegas.

La Roma Antigua también tiene su mujer fatal propia representada en varios personajes como Delia, conocida como la amante cruel de Tibulo. Delia rechaza a su marido para marchar con Tibulo, aunque al final también lo rechaza a él para poder estar con otro amante. Pero si hay que buscar a las mujeres símbolo de esta imagen de fatales nos encontramos con Cleopatra, Judith y Salomé.

Salomé sí parece ser un referente preciso y completo de mujer fatal; famosa por haber logrado la decapitación de Juan el Bautista bailando para el rey con la complicidad de su propia madre. Es imagen de la perversión sexual de una adolescente virgen que provoca los deseos más irrefrenables a través del baile anhelando poseer la cabeza del hombre que bautizó a Jesucristo (Camacho, 2006). Para conseguir su propósito utiliza una herra- 
mienta tan sutil como la seducción; el rey se rinde ante su encanto. Esta seducción sigue el canal de la danza árabe, elemento usado por otra fatal del siglo XX como Mata Hari, ayudando de esta manera a encasillarla dentro del estereotipo. Su influencia a lo largo de los tiempos es indudable, llegando a ser el estandarte de la mujer fatal más importante de finales del siglo XIX. El propio Ruben Darío lo recoge en el siguiente poema:

\author{
En el país de las Alegorías \\ Salomé siempre danza, \\ ante el tiarado Herodes, \\ eternamente; \\ y la cabeza de Juan el Bautista, \\ ante quien tiemblan los leones, \\ cae al hachazo. Sangre llueve. \\ Pues la rosa sexual \\ al entreabrirse \\ conmueve todo lo que existe, \\ con su efluvio carnal \\ y con su enigma espiritual. (Darío, En el país de las Alegoría, 2010)
}

Lo que hace única y perversa a Salomé es el objeto de la seducción, ya que no seduce a Juan sino a su padrastro Herodes, lo cual conlleva una importante pulsión de incesto aunque no existe relación consanguínea directa, sino más bien consideraríamos un incesto de afinidad. Mujer fatal semejante y con este matiz no parece repetirse.

Cleopatra, la reina egipcia, es otro personaje rodeado de mitos y perversiones. Calificativos como valiente y gran estratega han modelado su imagen. Egipto necesitó de buenos negociadores para conseguir beneficios, ahí es donde nace la imagen fatal de Cleopatra con sus artes amatorias junto a la excentricidad y el despotismo. Así, la imagen que queda de ella es la de una fatal insaciable en sus apetitos sexuales, una mujer sensual y hermosa que cuidaba su piel con baños de esperma; una mujer que eliminaba sin piedad a los esclavos- amantes tras haber pasado con ellos noches de amor y sexo. En este sentido, el personaje histórico se ve eclipsado por la leyenda creada ante la necesidad de explicar su éxito basado en estrategias que no compiten con las cualidades que históricamente se reservan a un rey, como su diplomacia, inteligencia y valor.

En las tradiciones judías fue Lilith la primera mujer creada por Dios. Mezcla de mujer y serpiente la podemos catalogar como la perfecta encarnación del diablo. Hecha de suciedad y heces, se rebeló e incluso se atrevió a demandar la igualdad entre sexos cuando se niega a colocarse debajo de Adán durante el coito. No dejándose forzar desapareció, libre, en el aire y parece encarnar los miedos masculinos sobre la impotencia, la debilidad y la sexualidad femenina, su afirmación e independencia. «Rameras, diablesas y mujeres antinaturalmente rebeldes son la misma cosa, pues Lilith fue realmente el primer ejemplo de esa horrible criatura que más tarde se llamará mujer emancipada» (Bornay, 1990). Fue la primera, pero no la última en causar problemas a los hombres. Aparte de las ya citadas, 
Betsabé impactó con su belleza al rey David, que por ella cometió adulterio y mandó matar a su marido. Judith, para liberar a su pueblo, sedujo a Holofernes y luego lo degolló. También María Magdalena fue prototipo de prostituta y pecadora, sin embargo, en los últimos años, hay quienes la designan como compañera y heredera del legado de Jesucristo.

Desde Lilith la Iglesia no ha dejado de condenar a las mujeres diabólicas que se atrevieron a usar libremente su sexualidad y alcanzar la independencia ante los varones. Un claro ejemplo es la caza de brujas. A finales del siglo XIV se convirtieron en objeto de persecución y tortura. En 1648, la Iglesia declaró la brujería crimen exceptum y permitía la tortura antes del juicio. La Santa Inquisición se encargó de ello. El hecho de que fueran casi siempre mujeres las acusadas se explica por su relación con el demonio, de quien se suponen intermediarias, constituyendo una amenaza para los hombres que debían evitar el contacto físico con ellas. En toda Europa se realizaron ejecuciones masivas de brujas.

Algunos de los casos expuestos tienen en común el haberse atrevido a participar en el mundo patriarcal, y también señalamos cómo a los castigos físicos se les agregan otros a manera de represión moral y social. El castigo más directo es quizás el de haberlas etiquetado para la historia como mujeres fatales.

\section{La mujer fatal: fuente de inspiración en el arte}

\subsection{Literatura}

Hemos podido comprobar en el apartado anterior que las concepciones de mujer fatal se han mezclado en la historia con mitos y miedos, en función de la cultura y del momento en el que se presentaban. El arte es tanto una forma de conocimiento como una manera de comunicación. Así, la dimensión sobrenatural de la mujer fatal se relaciona con la narración de historias. Encontramos a la mujer como necesidad de expresión de los miedos que se han venido dando en la historia y en la literatura.

En el siglo XIX, los roles sociales se cuestionaron y empezaron a alterarse, tomando las mujeres el papel de protagonista en muchos casos. Los hombres comenzaban a darse cuenta de la «incursión» de las mujeres en su mundo. Así, el escritor de esta época convierte la reivindicación femenina en una nueva perversión. Y, ¿cómo catalizar esos miedos? La respuesta es clara: la mujer fatal. Se veía como antiheroína, causante de males, culpable de las frustraciones de los hombres, debía ser controlada. La mujer fatal resurge con fuerza y su figura adquiere aspectos definidos.

Las chicas galantes que aparecen en la literatura son mujeres suficientemente capaces de adoctrinar al hombre en los juegos del amor y la palabra. Son amorosas, coquetas, conocen mil formas de seducción para volver loco al cliente, pero también poseen altos vuelos intelectuales, y es precisamente en esta capacidad para equipararse intelectual y culturalmente al hombre, donde se alcanza el mayor grado de perversión. No hay mayor placer que el que pasa por el filtro de la inteligencia. (Camacho, 2006)

Una mujer fatal representada «como fuerza ciega de la Naturaleza, realidad seductora pero indiferenciada, ninfa insaciable, virgen equívoca, prostituta que vampiriza a los 
hombres, belleza reptiliana, primitiva y fatal» (Puleo, 1997: 170). Una mujer que para muchos teóricos es mezcla de excitación sexual y miedo que ella misma suscita ya que el hombre occidental se veía amenazado por clases consideradas inferiores, entre ellas las mujeres. Se llegaba a una mitificación del cuerpo como consecuencia de los temores masculinos.

Los escritores han tenido su acercamiento particular a este modelo de mujer. En Bécquer, por ejemplo, la mujer lleva al amante a la locura, a la muerte, a matar a un ser querido. En Baudelaire, por su parte, el sexo «débil» simboliza el mal, el nuevo ángel caído, hermoso y mortal, llevando al hombre a lo más oscuro de su personalidad y presentando un carácter sobrehumano. Es una fruta deseada, una dulce tentación, aunque detrás de su goce se esconden terribles desventuras. Su poder ciega al hombre que se condena hacia su propia destrucción.

\author{
Tú que, como un golpe de cuchillo, \\ en mi corazón plañidero entraste; \\ tú que, fuerte como un rebaño \\ de demonios, viniste, loca y engalanada. \\ De mi espíritu humillado \\ hacer tu cama y tu dominio; \\ - infame a quien estoy atado \\ como el forzado a la cadena. (Baudelaire, El vampiro, 2009)
}

Un autor como Cortázar adapta los estereotipos de la diosa Circe, que sirven de inspiración, y en base a ellos reinventa a una mujer fatal paradigmática atribuyéndole las mismas características a su personaje femenino, Delia. Pero, ¿cuáles son los mecanismos de seducción? Vemos una bella y sabia Delia aplicando el arte culinario con dulzura para así seducir y traer consigo al mismo tiempo peligro; también en ambas aparece la confrontación de sus víctimas masculinas con animales como cerdos o cucarachas; una manera sutil de plasmar la humillación por medio de símbolos. Incluso ambas comparten la capacidad de maquinar intrigas y tejer conspiraciones a modo de araña con un telón de fondo que refleja la feminidad fatal.

Bécquer, en «El beso», repite la figura aunque con matices fantásticos. En esta historia el protagonista se enamora de una estatua de piedra para jactarse de ella ante sus amigos. Sin embargo, el destino trágico no está lejos: al abrazarla, la estatua, mata de una bofetada al desventurado. Según Woolsey (1964), pareciera que Bécquer desea decirnos que la influencia de un amor no correspondido es poderoso como para trascender la vida.

El joven ni oyó siquiera las palabras de sus amigos y tambaleando y como pudo llegó a la tumba y aproximóse a la estatua; pero al tenderle los brazos resonó un grito de horror en el templo. Arrojando sangre por ojos, boca y nariz, había caído desplomado y con la cara deshecha al pie del sepulcro. (Bécquer, El beso, 2010) 
Por otra parte, a un autor como José Martí la mujer fatal le inspira un ser martirizador, una enemiga, como se observa en los siguientes versos:

\author{
¡Dios las maldiga! Frívolas e impuras \\ Guardan tal vez el cuerpo con recato \\ Como un vaso de Sevres donde humean \\ Hidras ardientes y espantosos trasgos \\ ¡Dios las maldiga!, y si pueda sepulte \\ Todo rostro que el alma real oculte! (Martí, Dios las maldiga, 2001)
}

La lista de mujeres fatales se podría extender casi de manera interminable. Hemos hecho una incursión en la mujer fatal como inspiración literaria en algunas de sus figuras, especialmente del siglo XIX, y hemos comprobado la fuerza que esas mujeres adquieren por sí mismas. La riqueza de este periodo histórico contribuyó a potenciar la figura de este personaje y su influencia resultó decisiva a la hora de asimilar culturalmente los estereotipos creados.

\title{
3.2 Cine
}

La creación artística es una función esencial del ser humano; arte y hombre son inseparables. El lenguaje artístico además de ser una forma de conocimiento, es un medio de comunicación. Entre los distintos lenguajes artísticos, ya sea el cine, la arquitectura, la escultura, la literatura se dan intercambios que enriquecen la expresión artística. Así pues, vemos cómo en la era clásica ya se representaba tanto en literatura como en otras artes la figura de la mujer hechicera, cautivadora y sutilmente manipuladora; a lo largo de la historia hemos observado cómo ese símbolo ha evolucionado y ha dado lugar a infinidad de «mujeres fatales» que de manera brillante ha recogido la pintura y, en el siglo XX, el cine.

Un icono cinematográfico destacado es el de la mujer, y la mujer fatal ha encontrado una forma completa de difundirse como estereotipo. El cine le brinda la oportunidad no sólo de ser leída, sino vista y escuchada.

La iconografía es explícitamente sexual, de la misma manera que explícitamente violenta a menudo: largos cabellos (rubios u oscuros), maquillaje, y joyas. Cigarillos con sus rastros difuminados de humo pueden convertirse en signos de sensualidad oscura e inmoral, y la iconografía de la violencia (principalmente armas) es un símbolo específico (como lo es probablemente el cigarillo) de su antinatural poder fálico. La femme fatale está caracterizada por sus largas y espléndidas piernas [...]. (Place, 1980)

Hollywood, en sus primeros pasos, cohibido por la corriente puritana, no se atrevía a introducir figuras de mujeres seductoras y perversas, y se centró en la ingenua inocente y frágil. Fue en Europa donde, en las primeras décadas del siglo XX empezaron a surgir imágenes frías, escandalosas, devora-hombres, y fuertemente seductoras. Heredera de 
las féminas destructivas pintadas por Münch o Klimt, el cine danés introdujo la figura de la vamp. Su seducción es perversa. El cine italiano también presenta a su vamp latina, la gran prostituta mediterránea, adornada con joyas y plumas, lasciva y dominadora (Cruzado, 2002).

El cine norteamericano se rindió al poder de estas vampiresas y acabó importando el estereotipo (Alsina Thevenet, 1993). Son mujeres oscuras que, aunque no chupan literalmente la sangre a sus víctimas, sí que los explotan sexual y económicamente hasta convertirlos en una sombra de sí mismos. Theda Bara fue escogida por la Fox y la convirtió en la primera estrella prefabricada por la industria. Teñido el pelo de negro y con una biografía llena de misterios y exostismo dio vida en la pantalla a figuras de mujeres tan fatales como Carmen, Salomé o Cleopatra. De Europa llegaron Greta Garbo, que representaba a una mujer inaccesible, misteriosa y sensual, y Marlene Dietrich, protagonista de El ángel azul, tal y como anotamos en la introducción, que personificó el deseo.

A partir de los años treinta destacan dos géneros que abonaron el terreno para la aparición de la mujer fatal: el negro y el de terror. La mujer fatal o vampiresa encaja perfectamente en el primero, que vivió su periodo más fructífero entre los años 30 y 50, y que nos ha dejado imágenes difíciles de borrar de nuestras retinas, como la de Gilda (Gilda, Charles Vidor, 1946) quitándose su guante. En ella, una diva como Rita Hayworth aparece afirmando su independencia existencial. En la película se descubre un elemento que devela la verdad oculta tras el telón de las mujeres fatales: la necesidad del hombre por controlar a la mujer transgresora de las normas que ellos crearon y que les favorecen. «Gilda» sirve así como un autodiagnóstico de las frustraciones que mueven a la sociedad a expresarse, culpando de todos los males del mundo a quien ve como la suma de todos sus miedos. En cuanto al cine negro, surge como reflejo de los conflictos del siglo XX, marcado por los vaivenes de la economía, la violencia y la lucha por el poder. En este contexto el personaje femenino desarrolla un papel importantísimo siendo dueña de su destino, es dominadora en lugar de sumisa, como había venido siendo hasta ahora. Utiliza su sexualidad para lograr sus objetivos, que normalmente tienen que ver con el poder y el dinero. Alejada de los recurrentes roles femeninos, la mujer fatal, es núcleo de la intriga.

La caracteriza la fatalidad, la desdicha, la desventura que transmite al varón. Cautivado, a veces esconde en su interior lo perverso hasta que ella decida mostrarlo. Es una mujer cargada de sexualidad y erotismo acentuado por un rostro impasible, una mirada penetrante, una larga melena, unas curvas sinuosas y sus andares felinos. Ellas son conscientes de su poder y hacen todo lo posible por atrapar a quienes sientan el deseo de alcanzarlas. «La protagonista femenina del cine negro se presenta, por tanto, como deseable pero a la vez fuerte y peligrosa, salvaje como una pantera; el hombre tiene que controlarla y someterla para evitar ser destruido por ella. No olvidemos que la mujer salvaje está íntimamente ligada a la maga, a la hechicera, a la mujer con poderes sobrenaturales» (Cruzado, 2009). El sexo se trivializa y se emplea para saciar las ansias de riqueza, de estar rodeada de lujo. Para lograr ascenso social está dispuesta a entrar en el mundo del crimen y es capaz de eliminar a quien pueda ser un obstáculo para sus ambiciones. Su maldad no tiene límites; encarnan el pecado y la depravación más absoluta. Ellas mismas son las encargadas de matar como en Eva al desnudo, o mejor aún, convencen al amante 
para que realice el trabajo sucio como en El cartero siempre llama dos veces. La mujer perversa del cine negro presenta variantes. Está la chica del gánster, que no es más que un simple trofeo, la aventurera, que es cómplice, activa y no sometida, encontramos también a la «lady dark» sensual e inteligente que sabe bien lo que quiere y juega con el sexo para conseguirlo, la chica buena metida en líos y finalmente citaremos a la fatal con mayúsculas que encarna todas las maldades, además de la seducción, el riesgo, la inmoralidad y la destrucción. Sin embargo, en estas producciones suele aparecer, aunque en mucha menor medida, el contrapunto, el 'ángel', la mujer buena, pasiva, sumisa y silenciosa, encerrada en el hogar, que ofrece volver al buen camino.

\section{Crítica feminista}

Ya vimos en la introducción cómo desde tiempos remotos se ha identificado a la mujer con el mal y al hombre con el bien. También hemos podido comprobar cómo ha evolucionado ese concepto a lo largo de distintas épocas y cómo aparece reflejado en los distintos periodos literarios que conforman la historia de la literatura.

En el siglo XX hay una postura de defensa de las mujeres con el fin de contrarrestar la opresión machista. Así, surge en los años sesenta el feminismo como una importante fuerza política en el mundo occidental. La lucha estaba orientada hacia un cambio político y social, aunque luego la acción se extendió al dominio de la cultura, entrando poco a poco en el ámbito de la teoría y de la crítica literaria. El hecho de que, en el feminismo, el énfasis se haya puesto sobre todo en cuestiones políticas ha provocado la frecuente identificación de la mujer con otros grupos oprimidos, como los negros o la clase obrera, aunque ya Simone de Beauvoir recordaba que las mujeres no eran ni una minoría ni un producto de la historia. Nosotros vamos a distinguir dos críticas feministas: la angloamericana y la francesa.

\subsection{Crítica feminista angloamericana}

El impactó que causó la obra Sexual politics, de Kate Millet, la convierte en la precursora de la crítica feminista angloamericana enfrentada al New Criticism al defender la necesidad de atender a los contextos sociales y culturales para poder entender en su totalidad una obra literaria.

Gran madre del feminismo es Virginia Woolf cuyos textos constituyen aún hoy una referencia fundamental e inevitable del pensamiento crítico femenino. Como autora de novelas y cuentos, ha hecho emerger el punto de vista femenino. Sus ensayos críticos se dirigen en primer lugar a la reflexión sobre el papel de la mujer intelectual y sobre el sentido de una tradición en femenino.

Hay novelas que son un ejemplo de literatura femenina en las que las mujeres son las protagonistas. Un ejemplo es Orlando, donde se observa el problema de la identidad. En los ensayos, la autora representa su reflexión sobre el papel de la mujer artista, destacando A Room of One's Own (Gnisci, 2002). Según Woolf, en el siglo XVIII las mujeres empezaron a escribir y, sobre todo, a cobrar: el dinero confirió dignidad a su actividad 
intelectual que había sido relegada hasta entonces a la esfera privada, al margen de la sociedad.

Una de las vertientes más fértiles de la crítica literaria feminista es la denominada «imágenes de la mujer» que surge de la obra Images of Women in Fiction: Feminist Perspectives, que recogía una serie de ensayos centrados en el estudio de la imagen de la mujer en la literatura desde el presupuesto básico de que esa imagen es una distorsión de la realidad. Se piensa que la literatura sólo ha ofrecido imágenes falsas de la mujer y que debería ofrecer una imagen real, centrándose en las preocupaciones reales de las mujeres y en sus comportamientos reales porque sólo así se consigue que la literatura sirva para la vida enriqueciendo a los lectores (Viñas Piquer, 2007). Cuando este modelo fue perdiendo fuerza, hacia 1975, la crítica feminista empezó a centrarse en obras escritas por mujeres; en esta línea destacan, afirmando que es la sociedad, y no la biología, lo que conforma una percepción literaria del mundo propia de las mujeres. Ellas demostraron cómo la ideología machista dominante en el siglo XIX concebía la creatividad artística como una cualidad específicamente masculina llamando la atención sobre la dificultad de las mujeres para escribir en dichas circunstancias. Mujeres que deben conformarse con las imágenes creadas por los hombres, entre las que encontramos les femmes fatales, porque a ellas se les niega el derecho a crear sus propias imágenes. La mujer vista como una criatura pasiva y dócil, sin una fuerte personalidad, una criatura que no busca complacerse a sí misma, sino a los demás y, sobre todo, a su marido. Sin embargo, ante estas mujeres ángeles existen las mujeres objeto de nuestro estudio: mujeres monstruo que quieren tener su propia personalidad y consiguen seducir a los hombres y robarles su energía creadora. Estas mujeres resultan para el hombre monstruosas precisamente por no ser femeninas. La literatura satírica se sirve con frecuencia del monstruo femenino y deviene literatura claramente misógina. Esta imagen de la mujer monstruo en la sociedad explica por qué tantas mujeres han presentado aversión hacia sus propios cuerpos.

Así pues, está la idealización masculina de la mujer y, por otra, el miedo del hombre a la feminidad. Dualidad entre ángel y monstruo que, tal y como comenta Viñas Piquer, aparece enfrentada en el cuento de Grimm «La pequeña Blancanieves» donde encontramos a la malvada bruja frente a la hermosa joven, pálida, buena, dulce e ingenua. En este contexto es necesario resaltar cómo psicoanalistas de la talla de Freud y Jung observaron que los cuentos de hadas y mitos suelen expresar e imponer los axiomas de la cultura con más precisión que los textos literarios.

\subsection{Teoría feminista francesa}

Destaca una autora como Simone de Beauvoir con su libro El segundo sexo, en el que se concentran las bases del feminismo moderno. Ella decía que la feminidad es un factor cultural, que no se nace mujer, sino que se llega a serlo, siendo la opresión machista la que impone determinados modelos sociales de feminidad y tratando de convencer de que sólo esos son los modelos naturales.

De la revuelta estudiantil del Mayo del 68 surgió un nuevo feminismo francés que 
creció en un ambiente intelectual muy politizado y bajo la influencia del marxismo y el psicoanálisis. El feminismo francés presenta un carácter marcadamente intelectual. En general podemos afirmar que el feminismo francés posterior a Simone de Beauvoir no busca la igualdad entre hombres y mujeres, sino que se interesa más por la cuestión de la diferencia; más exactamente: por la especificidad de la mujer.

\section{BIBLIOGRAFÍA}

Alsina Thevenet, H. (1993): Historia del cine americano. Barcelona: Laertes.

Álvarez Hidalgo, F. (1997): Luminarias: http://poesiadelmomento.com/luminarias/ (27-08-2011).

Baudelaire, Ch. (2009): Las flores del mal. Madrid. Cátedra.

Bécquer, G. A. (2010): Leyendas. Madrid. Espasa-Calpe.

Bornay, E. (1990): Las hijas de Lilith. Madrid: Cátedra.

Camacho, J. M. (2006): «Del fragilis sexus a la rebellio carnis. La invención de la mujer fatal en la literatura de fin de siglo». En: Cuadernos de Literatura, Bogotá, 10, 22-36.

Cruzado, A. (2009): «La mujer como encarnación del mal y los prototipos femeninos de perversidad, de las escrituras al cine». En: Revista Internacional de Culturas \& Literaturas, 8: http:// www.escritorasyescrituras.com/revista.php/8/63 (15-06-2011).

Darío, R. (2010): Cantos de vida y esperanza. Barcelona: Linkgua.

Dijkstra, B. (1994): Ídolos de perversidad. La imagen de la mujer en la cultura de fin de siglo. Madrid: Debate.

Gnisci, A. (2002): «Los estudios sobre mujeres y los estudios de género». En: Introducción a la literatura comparada. Barcelona: Crítica.

González Ovies, A. (1994): «Mito: masculino singular». En: José Luis Caramés, Santiago González (eds.): Género y sexo en el discurso artístico. Oviedo: Servicio de Publicaciones de la Universidad de Oviedo.

Heredia, J. M. de (1893): Les Trophées: http://www.poesiaspoemas.com/jose-maria-de-heredia/ jason-y-medea (25-08-2011).

Houvenaghel, E. (2008): «El eterno retorno de la mujer fatal en Circe de Julio Cortázar». En: Bulletin of Hispanic Studies, 85, 6, 853-866.

Pedraza, P. (1991): La bella, enigma y pesadilla (Esfinge, Medusa, Pantera ...). Barcelona: Tusquets.

Place, J. (1980): «Woman in film noir». En: E. Ann Kaplan (ed): Woman in film noir. Londres: BFI, 35-54.

Puleo, A. (1997): «Mujer, sexualidad y mal en la filosofía contemporánea». En: Daimon, 14, enero-junio, 167-172.

Viñas Piquer, D. (2007): Historia de la crítica literaria. Barcelona: Ariel. 
Volpatti, L. (1994): Sul braccio dei colei. Breve viaggio letterario nella perfidia femminile. Milano: Baldini \& Castoldi.

Woolsey, W. (1964): «La mujer inalcanzable como tema en ciertas leyendas de Bécquer». En: Hispania, Lubbock, 47, 2, 277-281.

\section{FATALNA ŽENSKA}

Ključne besede: ženska, literatura, film, femme fatale, feministična kritika

Naša zgodovina je polna mitov in topik. Tako je tudi podoba fatalne ženske pogosta v delih vseh obdobij in krajev. Avtor članka najprej analizira, kako sta zgodovina in literatura vztrajno prikazovali in opredeljevali te ženske, in nato predstavi primere, ki izvirajo iz Stare Grčije. Umetnost se napaja z njihovo močjo zapeljevanja in članek pojasnjuje, kako se je ta femme fatale pojavila v literaturi in filmu. Članek sklene kratek pregled različnih utemeljitev glede ženske in feminizma, s katerimi se je literarna kritika opredelila do tega vprašanja. 